\title{
Análise socioeconômica do turismo comunitário na Comunidade Indígena Nova Esperança, RDS Puranga Conquista (AM)
}

\section{Socioeconomic analysis of community tourism in the Indigenous Community Nova Esperança, RDS Puranga Conquista (AM, Brazil)}

\author{
Nailza Pereira Porto, Ana Rosa Guimarães Bastos Proença
}

RESUMO: O turismo é uma das alternativas de uso público das Áreas Protegidas (AP), portanto é imprescindível que seja ordenado de forma a contribuir com a preservação socioambiental, além de proporcionar emprego e renda aos moradores locais e do entorno dessas áreas. Nesse contexto, tem-se o Turismo Comunitário (TC), um planejamento ou forma de turismo aliado ao desenvolvimento local e ao protagonismo comunitário. Assim, este artigo tem como objetivo apresentar análise socioeconômica do turismo comunitário na Comunidade Indígena Nova Esperança (AM). A comunidade localiza-se na Reserva de Desenvolvimento Sustentável (RDS) Puranga Conquista, no estado do Amazonas (BR) a cerca de $81 \mathrm{~km}$ da capital, Manaus. A pesquisa tem caráter qualitativo e quantitativo, utilizando-se de levantamento bibliográfico, documental e pesquisa de campo com as técnicas pesquisa participante, com aplicação de formulários e oficinas com ferramentas participativas para mensurar a contribuição das principais atividades econômicas na comunidade, levando em consideração as vantagens comparativas. Tais técnicas, tiveram a finalidade de demonstrar qual a contribuição da atividade turística na complementariedade das atividades tradicionais, não apenas no aspecto financeiro como também culturais e ambientais. A partir disso, se evidencia a importância da pluralidade de atividades econômicas para superar a sazonalidade turística que influencia diretamente no faturamento das famílias residentes em RDS's. Como contribuição, as informações apresentadas poderão ser relevantes para o planejamento do turismo comunitário no local, buscando minimizar os impactos e otimizar os recursos para a operacionalização e a compatibilização das atividades econômicas, culturais e ambientais da comunidade com a atividade turística.

PALAVRAS CHAVE: Amazonas; Análise Socioeconômica; Comunidade Indígena; Reserva de Desenvolvimento Sustentável; Turismo Comunitário. 


\section{ABSTRACT}

Tourism is one of the alternatives for public use of Protected Areas (AP), so it is essential that it be ordered to contribute as a socio-environmental preservation, providing employment and income to local residents and the surroundings of these areas. In this context, there is Community Tourism (TC) a planning or another form to do tourism allied to local development and community protagonism. Thus, this article goals to present a socioeconomic analysis of community tourism in the Indigenous Community Nova Esperança (AM). The community is in the Sustainable Development Reserve (RDS) Puranga Conquista, in the state of Amazonas (BR) about $81 \mathrm{~km}$ from the capital, Manaus. The research has a qualitative and quantitative character, using bibliographic, documentary and field research with participant research techniques, application of forms and workshops with participative tools to measure the contribution of the main economic activities in the community, considering the comparative advantages. These techniques were pointed at demonstrating the contribution of tourism activity in the complementarity of traditional activities, not only in the financial aspect but also cultural and environmental. From this, it is evident the importance in plurality of economic activities to overcome the touristic seasonality that directly influences the turnover of families residing in RDS. As a contribution, the information presented may be relevant to planning community tourism on lands, seeking to minimize impacts and optimize resources for the operationalization and compatibility economic, cultural and environmental communities activities of tourists activity.

KEYWORDS: Amazonas; Indigenous Community; Sustainable Development Reserve; Community Tourism.

\section{Introdução}

As Áreas Protegidas (AP) são um meio de combater a degradação das florestas e de promoção do desenvolvimento regional com sustentabilidade. Diversas estratégias estão sendo propostas a fim de ampliar e fortalecer estas áreas no Brasil, uma de destaque é o Plano Nacional de Áreas Protegidas (PNAP), que promove a conservação e o uso sustentável da biodiversidade, valorizando a cultura dos povos tradicionais (PNAP, 2006). Como estratégia de conservação, o uso público destas APs precisam ser ordenadas de forma a contribuir para a proteção e alternativa de emprego e renda para as comunidades locais. Entre as principais atividades praticadas nestas áreas, citam-se: recreativas, turismo, visitação, pesquisa e educação ambiental.

No âmbito do turismo, tem-se a crescente adesão ao turismo comunitário (TC), ou turismo de base comunitária (TBC), como planejamento ou outra forma de se fazer turismo em locais de pequena/média escala em países periféricos, se configurando como uma alternativa de renda, de socialização, de compromisso sociocultural e com os recursos naturais, buscando bases sustentáveis para seu desenvolvimento. 
Dentre as pesquisas de Turismo Comunitário muito se apresenta sobre as influências sociais e culturais ou de sua proposta em substituir em comunidades ou territórios de menor escala um turismo com caraterísticas predatórias, porém com uma carência de dados sobre a atividade econômica, na qual, corroboraria com as teorias que se vem desenvolvendo sobre o referido tema.

Traz-se essa lacuna, por se evidenciar em campo a (também) importante influência no engajamento e motivação que a geração de renda causa nas comunidades que adentram redes ou iniciativas de turismo comunitário, pois a atividade é entendida tanto como fenômeno social e como trabalho (não-formal) para os comunitários. Umas das formas de se organizar as iniciativas de turismo comunitário é por meio da criação de redes ou roteiros, visando a colaboração entre comunidades.

Diante disso, ressalta-se o Roteiro de Turismo Comunitário no Baixo Rio Negro (AM), Roteiro TUCORIN, com a inexistência de estudos socioeconômicos prévios à sua criação, trazendo a necessidade de se responder a algumas inquietações relacionadas à sustentabilidade do turismo em Unidade de Conservação (UCs), nesse caso especificamente em Reserva de Desenvolvimento Sustentável (RDS), por o roteiro incluir duas RDS: a RDS Puranga Conquista (Estadual) e RDS do Tupé (Municipal). Entretanto, devido a abrangência territorial das RDs do Roteiro, optou-se por selecionar a Comunidade Indígena Nova Esperança (AM), localizada na RDS Puranga conquista, como estudo de caso por se ter um envolvimento maior e portas abertas com os comunitários.

Assim, este artigo teve como objetivo apresentar análise socioeconômica do turismo comunitário na Comunidade Indígena Nova Esperança (AM). Identificou-se também as principais atividades econômicas praticadas na comunidade, com o intuito de contribuir para a carência de dados socioeconômicos sobre Turismo Comunitário, além de propiciar reflexões sobre turismo comunitário e sustentabilidade, e turismo em área indígena.

\section{Turismo comunitário e o Roteiro TUCORIN}

A não concordância de um termo único sobre 'Turismo Comunitário' vem sendo um dos desafios de definição deste construto e de levantamento bibliográfico sobre. Sua polissemia varia desde algo mais global ao mais situacional, dependendo do/a autor(a), de seu país, qual a área (rural ou urbano) e em qual tipo de grupo social sua pesquisa está inserida. Identificou-se no banco de dados da CAPES as seguintes variações: a) turismo de base comunitária; b) turismo comunitário; c) ecoturismo de base comunitária; d) turismo de base local; e) turismo solidário; f) turismo rural comunitário; e g) turismo rural sustentável ${ }^{1}$.

Essa apresentação polissêmica se faz necessária para entender a união de marcos históricos apontados por diferentes autores sobre como 
este surge e o que é Turismo Comunitário, no qual, o artigo trabalhará com esse termo por ser o mais 'simples' e 'global' entre os apresentados, além de melhor refletir a situação local do estudo.

Maldonado (2009, p. 26) apresenta que o Turismo Rural Comunitário (TRC) surge na América Latina em 1980, associado a "pressões mundiais do mercado turístico" sobre os patrimônios culturais e naturais dos povos indígenas e rurais devido ao crescimento de um segmento cultural e natural no turismo nessas áreas. Além disso, traz a possibilidade de gerar economia e trabalho a comunidades em situação de pobreza crônica, conjuntamente ao diálogo com a dimensão social e cultural destas, humanizando o turismo, valorizando as relações entre os diferentes atores sociais, indo além de uma atividade mercadológica de produção e consumo.

Bursztyn (2012) discorre que a busca por um mercado consciente, engajado e responsável é um grande desafio para a atividade turística. A economia solidária surge como uma nova "forma social de produção", uma alternativa da sociedade excluída dos grandes fluxos de capitais em se reorganizar, nos sentidos do trabalho clássico, em uma nova configuração produtiva, que possibilita a geração de renda e qualidade de vida.

Irving (2009) aponta que a formalização TBC só foi reconhecida, de fato, após a Eco-92 dentro da discussão de um turismo sustentável. No Brasil, a sustentabilidade do turismo com premissas no envolvimento comunitário surge, em primeiro momento, como tema de diálogo científico a partir do I Encontro Nacional de Turismo de Base Local (ENTBL), realizado em São Paulo, em 1997 (ibid, 2009).

Em substituição das formas convencionais do turismo, o Turismo de Base Comunitária (TBC) ou Turismo Comunitário (TC) "é aquele em que as comunidades de forma associativa organizam arranjos produtivos locais, possuindo o controle efetivo das terras e das atividades econômicas associadas à exploração do turismo" (CORIOLANO, p. 282).

Outro mecanismo importante de difusão do conceito de turismo comunitário são as "Redes", espaços para troca de experiências e fortalecimento da modalidade de um turismo alternativo e diferenciado como a rede TURISOL, TUCUN, REDTURS, a Central de Turismo Comunitário da Amazônia (CTCA), entre outros, compartilhando a mesma filosofia de promover e divulgar o turismo mais inclusivo e solidário em comunidades.

No Brasil já existem agências de turismo especializadas que trabalham especificamente para o público de TC. É o caso das agências: Turismo Consciente, Cia da Mochila, Ambiental, Pra que Rumo, Estação Gabiraba entre outras que são especializadas em roteiros não convencionais e exclusivos, geralmente fechando grupos de jovens adultos que buscam experiências ímpares de vida, por meio do contato mais direto com as comunidades receptoras.

Tratando-se do turismo quando adentra área protegidas, o Manual de Diretrizes para Visitação em Unidades de Conservação Brasileiras aponta 
entre seus 11 princípios para o planejamento e gestão da visita em UCs que "a visitação deve contribuir para a promoção do desenvolvimento econômico e social das comunidades locais" (BRASIL/MMA, 2006, p. 13). Isto é fundamental para garantir a preservação dos recursos naturais nela existentes, bem como a consecução dos benefícios indiretos de ordem ecológica, econômica, científica e social.

Um desafio que há no setor do turismo convencional no Estado do Amazonas é a integração desta atividade no âmbito das UCs proporcionando o envolvimento dos comunitários e políticas públicas. No Estado foi elaborado um Plano de Desenvolvimento Sustentável e Integrado da Região Metropolitana de Manaus levando em consideração um planejamento para dez anos de 2010 a 2020 (AMAZONAS, 2010). Este plano prevê como meta o fortalecimento e organização de atividades já existentes, como o turismo, em vias sustentáveis e de inclusão dos atores locais.

No município de Manaus, na região do Mosaico do Baixo Rio Negro a falta de uma participação mais ativa na atividade de turismo motivou os comunitários a desenvolverem iniciativas familiares e comunitárias direcionadas à recepção, hospedagem e alimentação. Assim, os comunitários se organizaram através de suas associações e foram pedir apoio para as organizações não-governamentais: a Nymuendaju ${ }^{2}$ e Instituto de Pesquisas Ecológicas ${ }^{3}$ (IPÊ). O objetivo dos comunitários era promover 0 turismo visando à geração de trabalho e renda, junto ao seu protagonismo na gestão da atividade.

Assim surgiu o Roteiro Tucorin, abrangendo seis comunidades (entre elas indígenas e ribeirinhas) de duas RDSs: a RDS Puranga Conquista e RDS do Tupé, cujo objetivo é valorizar o cotidiano das comunidades por meio da interação mais próxima entre turistas e comunitários (Figura 1). A Comunidade Indígena Nova Esperança faz parte deste roteiro estando "na oferta Norte" junta a mais duas comunidades ribeirinhas: São Sebastião (localizada também no rio Cuieiras) e Bela Vista do Jaraqui (Rio Negro).

Ressalta-se que a área em que a comunidade está sobreposta, em um passado recente, tinha como principal atividade econômica a derrubada de madeira para venda, para fabricação de espetinho por exemplo, além de empresa clandestina que retirava areia do rio sem permissão dos moradores e de órgãos oficiais. Assim, o turismo chega nas comunidades como outra opção de renda, com menos pressão antrópica pelo desmatamento, valorizando as belezas cênicas no Rio Negro e as socioculturalidades ali presentes. 


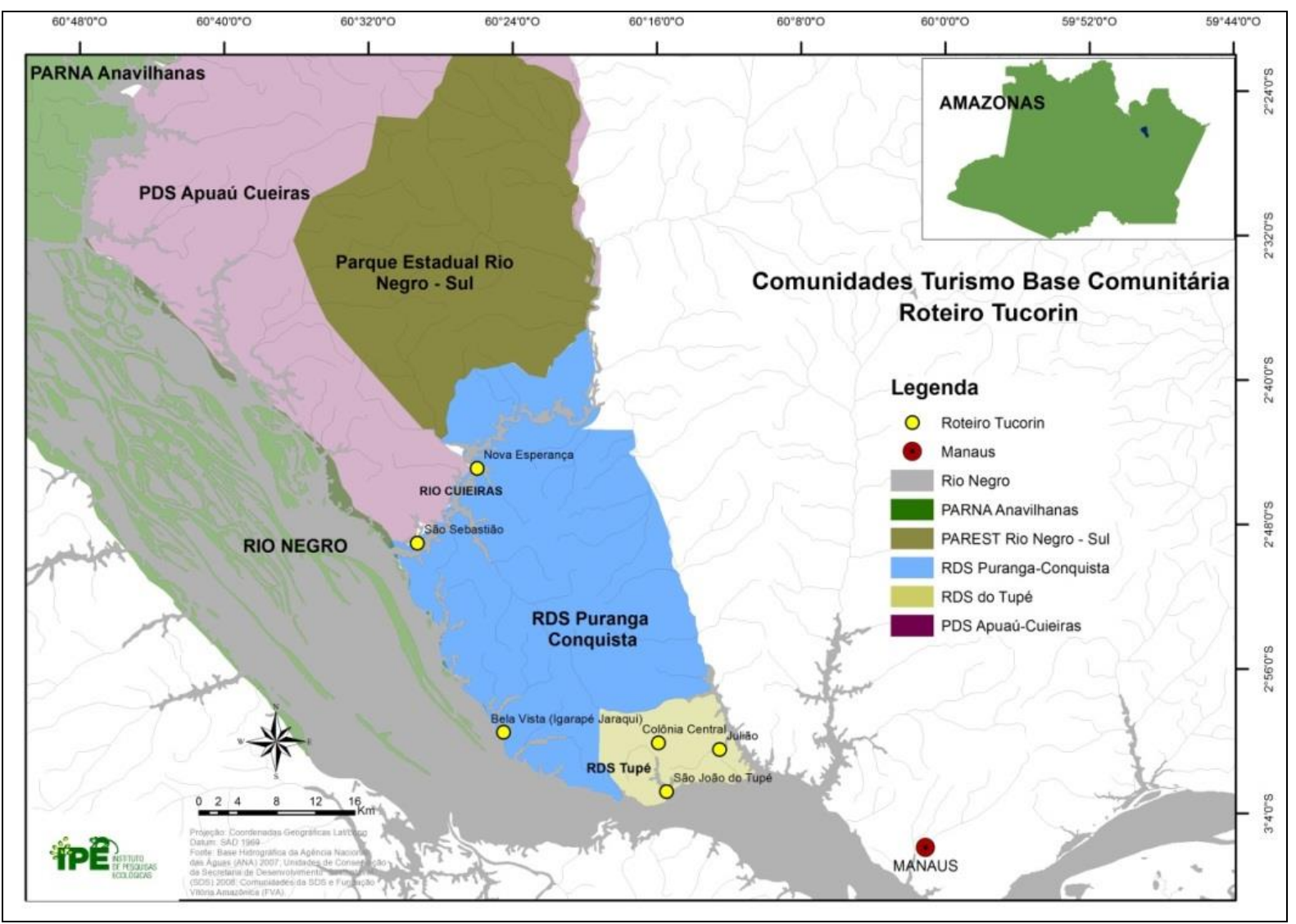

Figura 1: Localização das seis comunidades inseridas no Roteiro TUCORIN.

Figure 1: Location of the six communities whom integrate Roteiro TUCORIN.

Fonte: IPÊ, 2014. Source: IPÊ, 2014.

Atenta-se também a duas questões, uma regional e uma global: i) Os ciclos das águas no Amazonas. No período de seca do rio, o acesso às comunidades no Rio Cuieiras fica extremamente difícil, pois onde haviam rios, se tem bancos de areais. Esse fenômeno ocorre geralmente entre Agosto a Janeiro, sendo mais acentuado em Outubro; ii) Sazonalidade do turismo. Levando em consideração a proposta do turismo também enquanto gerador de renda, comunidades nesse contexto que já sofrem com a redução do turismo pelo ciclo das águas, tendem a diminuir ainda mais seus ganhos com a diminuição dos fluxos turísticos, devendo o turismo ser uma entre outras atividades econômicas. Façamos um parênteses aqui, de que se deve atentar no planejamento, se a diminuição do fluxo turístico está vinculado a esses dois fenômenos ou se (também) é um problema de comercialização e promoção do TBC. 


\section{Procedimentos Metodológicos}

A pesquisa teve como estudo de caso a comunidade Nova Esperança. Segundo Severino (2007), no estudo de caso, os dados devem ser coletados e registrados com o necessário rigor e seguindo todos os procedimentos da pesquisa de campo. Eles devem serem trabalhados mediante análise rigorosa e apresentados em relatórios qualificados.

A opção pela pesquisa participante, conforme propõe Brandão (2006), aproximou ainda mais as pesquisadoras dos sujeitos do universo a ser investigado, gerando um comprometimento, o qual, por conseguinte, também gera alternativas capazes de "[...] colocar o conhecimento social, obtido por meio de procedimentos científicos, a serviço de alguma forma de ação social transformadora".

Outro aspecto importante da pesquisa foi quanto à variedade de estratégias adotadas, o que Ihe imprimiu caráter quantitativo, qualitativo e exploratório. Os instrumentos utilizados na coleta de dados foram: formulários, observação, entrevistas informais, análises de documentos, relatórios técnicos e oficinas participativas. As oficinas tiveram por base 0 Roteiro Metodológico para elaboração do Plano de Manejo que propõem algumas ferramentas participativas que serviram de suporte para alcançar os resultados da pesquisa.

Este artigo é resultado da junção de dados primários e secundários das pesquisas feitas pelas autoras em diferentes momentos. A primeira ocorreu em 2013 e 2014 e a segunda em 2016 e 2018, sendo alguns dados atualizados, visando a colaboração entre os pesquisadores sobre um mesmo local de estudo em prol da comunidade e da publicação cientifica sobre.

\section{Comunidade Indígena Nova Esperança: uma breve descrição}

A Comunidade localiza-se na Reserva de Desenvolvimento Sustentável Puranga Conquista, na zona rural do Município de Manaus, dentro do Rio Cuieiras (Coordenadas geográficas: 20 74"83.33 S,

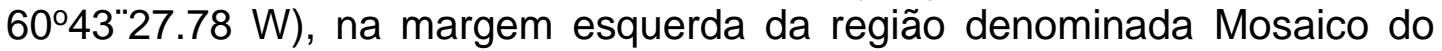
Baixo Rio Negro.

Essa comunidade foi fundada no ano 1996, como resultado da migração indígena oriunda do município de Santa Isabel do alto Rio Negro por motivos econômicos, sociais e de saúde. Atualmente possui 32 famílias da etnia Baré com grau direto de parentesco.

O fato das famílias serem parentes ajuda na organização social desta comunidade. A comunidade possui hábitos de trabalhos coletivos como: farinhada, multirões de limpeza, de produção agrícola e de produção de artesanato. As decisões ainda são pautadas no respeito ao casal mais velho da comunidade, matriarca e patriarca. Segundo dados coletados, a moradora que reside a mais tempo na comunidade tem vinte cinco anos de 
domicílio e a grande maioria dos moradores tem em média dez anos de residência.

Para Diegues (2000), os saberes tradicionais desempenham um papel fundamental para garantir a sustentabilidade social, econômica e ambiental na Amazônia, posto que estudar estes conhecimentos possibilita analisar os processos naturais da atividade humana no ambiente. Portanto, o envolvimento comunitário precisa se tornar cada vez mais positivo para que as populações destas áreas contribuam para a conservação e sustentabilidade destas áreas, sendo que a atividade de turismo comunitário poderá ser uma alternativa viável e apoiada nas comunidades que têm perfil para desenvolvê-lo. Algo que já se aplica à Comunidade Indígena Nova Esperança.

Na comunidade existem cerca de 20 artesãos. O artesanato (Figuras 2 e 3) produzido consiste em colares, brincos e pulseiras, todos confeccionados com sementes da região; canoa, remo e animais da fauna amazônica, em madeira; flecha, arco, zarabatana, peneira, trançados de tupés e urutu (cestarias em fibras).

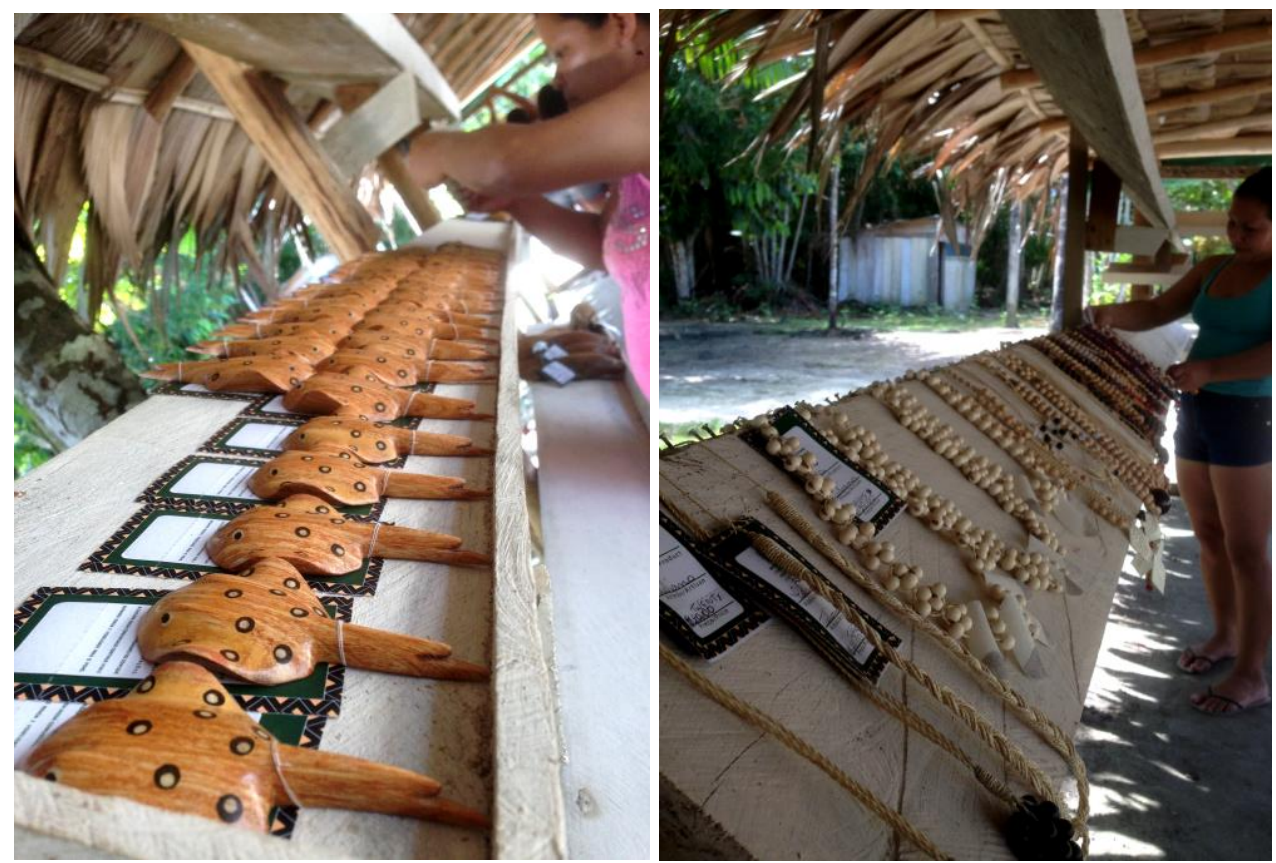

Figura 02 e 03: Artesães organizando suas produções para exibir aos turistas.

Figures 02 \& 03: Handicrafters organize their productions to showing to tourists.

Fonte: Proença, 2018. Source: Proença, 2018.

Algumas sementes são coletadas nas proximidades e foram cultivadas com esta finalidade, outras são compradas em Manaus. Para confecção do artesanato em madeira são utilizados resíduos de árvores caídas e de madeiras doadas pela Oficina Escola de Lutheria da Amazônia de procedência certificada pelo FSC - Forestry Stewardship Council (Conselho de Manejo Florestal). 
Enquanto estrutura, as casas da comunidade são de madeira, cobertas por zinco, com média de quatro cômodos e com banheiros de fossa séptica. Existem duas igrejas: uma católica, Igreja de Santa Luzia e uma evangélica, Congregação Evangélica Indígena Nova Salém. Tem-se o chapéu de palha, que funciona como centro comunitário, outro espaço em forma retangular coberto por palha para expor os artesanatos produzidos por todos na comunidade e um restaurante comunitário.

O campo de futebol da comunidade é tanto utilizado para hábitos esportivos dos comunitários, como para se confraternizar e interagir com os visitantes. Tem também, a opção de hospedagem na comunidade ficando em casa de um comunitário que fez um quarto e banheiro dentro de sua casa para receber os turistas. O quarto acomoda de 1 a 4 pessoas.

Na parte educacional, tem-se a Escola Municipal Puranga Pisasú que oferta ensino fundamental e médio, com professores do "Projeto Itinerante" vindos da capital e educação indígena com professor da própria comunidade, além da biblioteca indígena Uka.

Quanto a saúde, existe um posto da Fundação Nacional de Saúde (Funasa) com agentes de saúde indígenas capacitados para tratarem de pequenos problemas e vacinação. Atualmente são dois. Os médicos visitam as comunidades uma vez ao mês pela Secretaria Municipal de Saúde (SEMSA). Em 2012, o posto de saúde da comunidade foi reformado por meio de doação de turistas estrangeiros.

A geração de energia elétrica é feita por um motor comunitário, normalmente, com divisão do custo do diesel pelos comunitários, que chega a aproximadamente $\mathrm{R} \$ 26,00$ (Vinte e seis reais) por mês, por família. O uso do gerador é racionado: funciona quatro horas durante o dia e cinco durante a noite. Mesmo com a dificuldade de acesso à energia vinte e quatro horas por dia, $100 \%$ das famílias entrevistadas têm em média três aparelhos eletrônicos e quatro eletrodomésticos em suas residências. Na comunidade não chega sinal de celular. Em janiero de 2014, por meio do apoio da Secretaria de Educação Municipal (SEMED), devido ao ensino tecnológico na escola (para o ensino médio), se tem rede Wi-Fi.

A captação da água é feita por meio de poço artesiano que abastece todas as casas da comunidade. O poço está localizado num raio de 80 metros das residências. O tratamento dos resíduos sólidos é realizado pela queima e o aterramento. Os resíduos orgânicos servem como alimento para as criações de animais domésticos.

Devido a já mencionada multiplicidade de acessos aos rescursos naturais, há uma grande variedades de produtos da roça que ajudam na subsistência das famílias, como: goma, tucupi, tapioca, beju, farinha de tapioca e farinha de mandioca. Além de frutas e verduras, como: abacaxi Ananas comosus, mamão Carica papaya, cará Dioscorea spp., banana Musa sp., ingá Inga sp, cubiu Solanum topiro, pimenta Capsicum spp., macaxeira Manihot esculenta, batata doce Ipomoea batatas, jerimum Curcubita spp. e melancia Citrullus Lanatus. 
A composição da renda familiar se mostra diversificada pela pluralidade de atividades, como mostra a Figura 4.

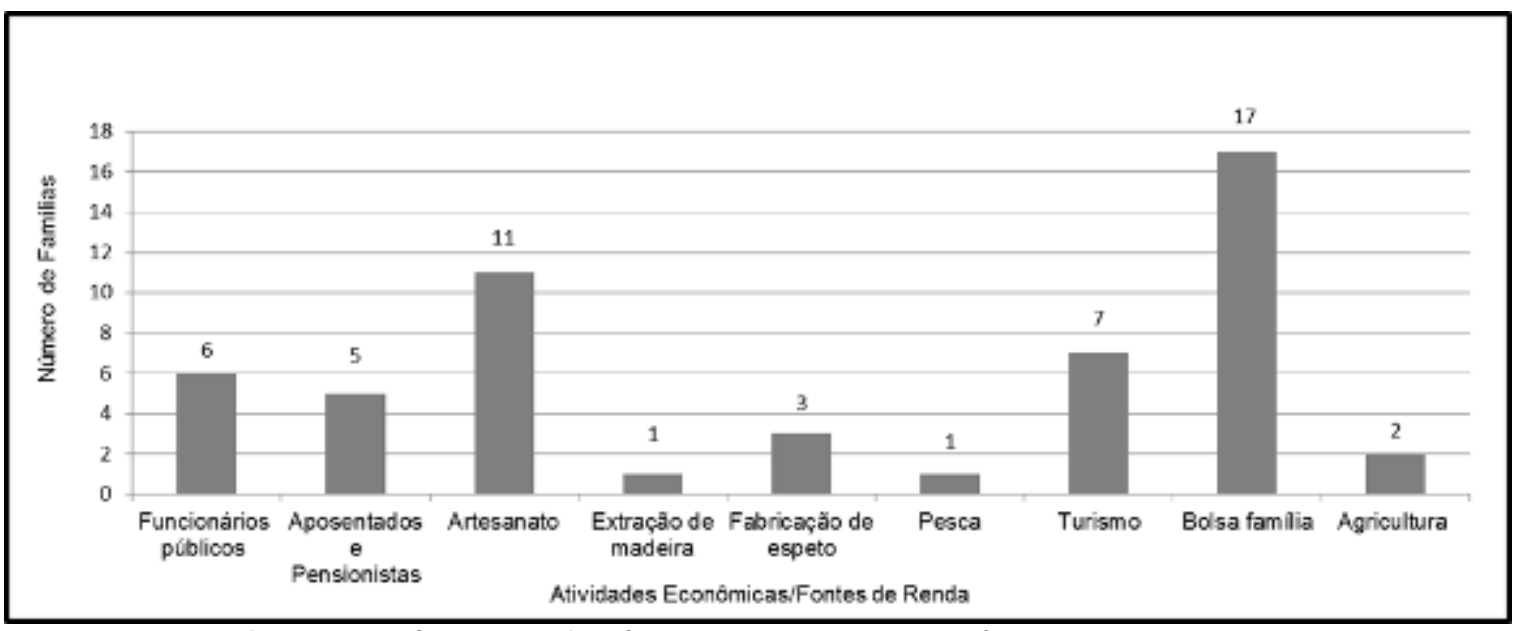

Figura 4: Número de famílias por atividade econômica - Nova Esperança

Figure 4: Family numbers for economic activities.

Fonte: Porto, 2013. Source: Porto, 2013.

As atividades econômicas que compõe as rendas familiares levantadas foram: artesanato, agricultura, espeto (utensílio em madeira descartável), pesca, extração de madeira e turismo. Outras fontes de rendimento levantadas foram: salários dos funcionários públicos, aposentados, pensionistas e bolsa família, totalizando nove fontes de receitas.

No período da pesquisa, quatro famílias apresentaram uma renda mensal de até um salário mínimo e outras quinze de um até três salários mínimos. O faturamento médio mensal da comunidade por família é de $\mathrm{R} \$$ 1748,52 (Um mil setecentos e quarenta e oito reais e cinquenta e dois centavos). Este resultado coloca em evidência pelo menos três fontes importantes de recurso como: bolsa família, artesanato e turismo. Além desses, alguns comunitários também recebem o bolsa-floresta e o seguro defeso (pago a pescadores cadastrados durante o período de interrupção da pesca de algumas espécies em rios do Amazonas).

Em relação aos aspectos culturais podem ser mencionadas as festividades: Festa de São Lazaro, comemorada em outubro, Festa de Santa Luzia, comemorada no mês de dezembro, e a Festa em comemoração ao dia do índio, sendo tradicionalmente realidade a "Dabucuri", dança também realizada pela etnia Baré. O futebol é a principal atividade de lazer diária tanto entre homens quanto entre mulheres.

Ocorre também atividades em prol da coletividade como os mutirões de limpeza ou para construção de algum espaço destinado ao uso comum. Todas as famílias que foram entrevistadas são membros da Associação Comunitária Indígena Baré dos Artesãos de Nova Esperança (ACIBANE) e contribuem com uma taxa mensal de $\mathrm{R} \$ 10,00$ (Dez reais). 


\section{A atividade turística na comunidade}

Por meio da metodologia participativa, linha do tempo, realizada na Comunidade Nova Esperança, constatou-se que, mesmo criada em 1996, a comunidade somente teve acesso a informações sobre o que era atividade turística em 2003, por meio de uma sensibilização da Amazonastur.

No ano de 2005 recebeu a primeira visita de turistas que vieram motivados pelo artesanato local. Em 2006, a comunidade elegeu como o ano do "auge" do turismo, pois quatro empresas começaram a frequentar a comunidade, levando turistas nacionais e internacionais (Figuras 5 e 6). Em 2008 e 2009 houve uma queda nas visitas, e isso fez com que os comunitários percebessem que poderiam incrementar a atividade, oferecendo outros atrativos turísticos além do artesanato.
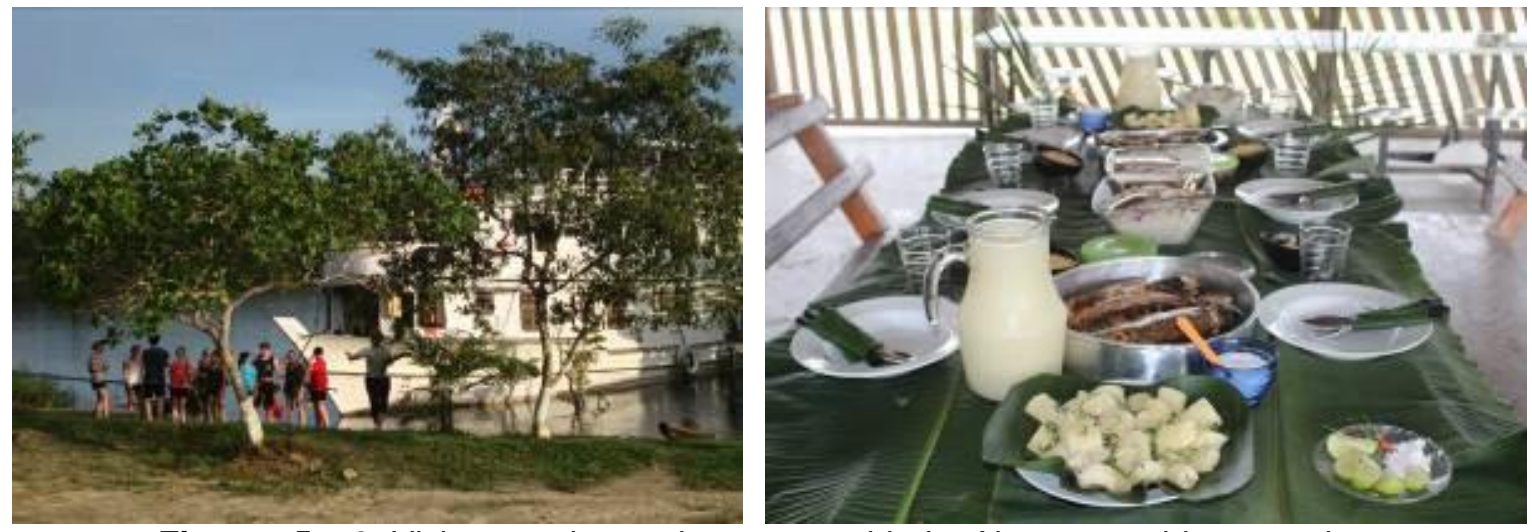

Figuras 5 e 6: Visitantes chegando na comunidade. Almoco servido aos turistas.

Figures 5 \& 6: Tourists landed in the community. The lunch served to tourists.

Fonte: PORTO, N.P., 2013. Source: PORTO, N.P., 2013.

Assim, em 2010, um grupo de 15 comunitários se organizou e se reuniu com a equipe do IPE, para juntos fazerem um levantamento sobre os possíveis atrativos locais. No mesmo ano, o grupo participou de oficinas de sensibilização e planejamento turístico, assim como de capacitações voltadas para a condução em trilhas e melhoria do acabamento das peças de artesanato.

Nos dois anos seguintes, os comunitários participaram de intercâmbios a projetos de turismo comunitário em outras cidades. Posteriormente, começaram a receber os primeiros grupos de "turistas comunitários" por meio da parceria com a Central de Turismo Comunitário na Amazônia já fazendo parte do Roteiro Tucorin. Os serviços que compõe a oferta turística disponibilizada pela comunidade dentro do Roteiro Tucorin são:

i. Refeição. Oferecida de forma casada, ou seja, já incluída na hospedagem, ou separada, para grupos maiores que não pernoitam na comunidade. Nas refeições, como almoço e jantar são oferecidos pratos à base de peixe de água doce, com acompanhamento de baião, feijão, arroz e farinha. A 
sobremesa são frutas regionais da época. O café da manhã é regional à base de frutas, macaxeira, beju, tapioca com tucumã e café com leite.

ii. Hospedagem. Oferecida na casa do comunitário em rede e/ou cama. $\mathrm{O}$ banheiro é privativo. A casa é construída em madeira e telhado de zinco e está localizada do meio do núcleo comunitário, ou seja, próximo da igreja, barração comunitário e escola.

iii. Farinhada. Experiência oferecida para a vivência mais interativa de finalização do processo da farinha, na fase de torragem. Esta atividade envolve o visitante durante uma hora na fabricação da farinha, sendo que uma pequena amostra do produto é oferecida como souvenir dentro de um cesto tecido em palha.

iv. Monitoria do artesanato. Atividade que envolve o serviço de monitoria na confecção de artesanato, com duração aproximada de uma hora. Nela, o visitante é orientado a confeccionar uma peça simples de artesanato e pode levá-la como souvenir. O processo de criação artística serve como um momento de interação entre visitante e artesão.

v. Canoagem. Atividade de contemplação com uma hora de duração. $O$ condutor comunitário leva o visitante de canoa a remo para passear no lago de igapó próximo à comunidade. A canoa tem capacidade para cinco pessoas e está equipada com coletes salva-vidas. Através desta atividade é possível avistar aves e botos, sendo que durante o percurso o visitante poderá tomar banho de rio.

Tais atividades podem ser analisadas economicamente com os fatores de: preço de venda, custo privado + social, horas trabalhadas, margem de contribuição e renda ao mês por unidade como apresentado na Tabela 1. Os cálculos e a descrição dos serviços foram com base na CMS Capacidade Máxima de Serviço.

Tabela 1: Despesas por serviço.

Table 1: Expenses for service.

\begin{tabular}{|c|c|c|c|c|c|c|c|}
\hline \multirow[b]{2}{*}{ Descrição dos Serviços } & \multirow{2}{*}{$\begin{array}{c}\text { Preço de } \\
\text { Venda }\end{array}$} & \multirow{2}{*}{$\begin{array}{c}\text { Custo } \\
\text { Privado } \\
\text { +Social }\end{array}$} & \multicolumn{3}{|c|}{ Horas Trabalhadas } & \multirow[b]{2}{*}{$\begin{array}{l}\text { Margem de } \\
\text { Contribuição }\end{array}$} & \multirow{2}{*}{$\begin{array}{l}\text { Renda ao } \\
\text { Mês, por } \\
\text { unidade }\end{array}$} \\
\hline & & & Horas & CMS & Valor & & \\
\hline Diária com alimentação & $\mathrm{R} \$ \quad 100.00$ & $\mathrm{R} \$ \quad 26.22$ & 8.97 & 53.53 & $\mathrm{R} \$ 34,54$ & $39 \%$ & $\mathrm{R} \$ 1448,25$ \\
\hline Diária sem alimentação & $\mathrm{R} \$ \quad 50.00$ & $\mathrm{R} \$ \quad 10.08$ & 5.96 & 80.54 & $\mathrm{R} \$ 22,96$ & $34 \%$ & $\mathrm{R} \$ 1178,92$ \\
\hline Diária sem alimentação - rede & 75.00 & $\mathrm{R} \$ \quad 26.14$ & 3.93 & 122.03 & $\mathrm{R} \$ 15,15$ & $34 \%$ & $\mathrm{R} \$ 1178,92$ \\
\hline Alimentação a parte (almoço ou jantar) & 25.00 & $\mathrm{R} \$ \quad 9.64$ & 3.06 & 156.69 & $\mathrm{R} \$ 11,80$ & $14 \%$ & $\mathrm{R} \$ 882,50$ \\
\hline Trilhas por grupo de até 10 pessoas & 50.00 & 3.96 & 1.48 & 324.32 & $\mathrm{R} \$ 5,70$ & $81 \%$ & $\mathrm{R} \$ 5475,03$ \\
\hline Farinhada para grupo de até 10 pessoas & 75.00 & 3.96 & 1.48 & 324.32 & $\mathrm{R} \$ 5,70$ & $87 \%$ & $\mathrm{R} \$ 8488,00$ \\
\hline $\begin{array}{l}\text { Canoagem para grupo de } 5 \text {, passeio de } \\
\text { canoa }\end{array}$ & 50.00 & 2.20 & 1.48 & 324.32 & $\mathrm{R} \$ 5,70$ & $84 \%$ & $\mathrm{R} \$ 5684,32$ \\
\hline $\begin{array}{l}\text { Monitoria na Oficina de Artesanato , p/ } 5 \\
\text { pessoas }\end{array}$ & 30.00 & 9.17 & 2.63 & 182.51 & $\mathrm{R} \$ 10,13$ & $36 \%$ & $\mathrm{R} \$ 1394,17$ \\
\hline Médias & 56.88 & $\mathrm{R} \$ 11.42$ & 3.62 & 196.03 & 13,96 & $51.12 \%$ & $\mathrm{R} \$ 3211,26$ \\
\hline
\end{tabular}

Fonte: PORTO, N.P. FILHO, L.F, 2013.

Source: PORTO, N.P. FILHO, L.F, 2013. 
Os resultados demonstram que tanto a média da margem de contribuição por mês por unidade de serviço quanto à média de renda mensal de cada serviço é positiva, ficando acima de um salário mínimo.

Este cálculo de despesas e custos reais praticados atualmente na comunidade Nova Esperança é satisfatório no que concerne ao retorno financeiro da atividade turística, pois a margem de contribuição positiva está acima de (50\%) do valor real dos custos dos serviços. Este é um indicador da existência de possíveis recursos para investimentos e melhorias em infraestrutura.

Analisando os dados do faturamento potencial dos oito serviços oferecidos na Comunidade Nova Esperança, tirando uma média ponderada, é possível obter o percentual da margem bruta como resultado da divisão entre a soma da renda potencial de cada um dos serviços pela média ponderada do faturamento potencial. Com isso, chega-se ao seguinte cálculo (Tabela 2):

Tabela 2: Cálculo da Margem Bruta

Table 2: Gross Margin Calculation

\begin{tabular}{|c|c|c|c|c|c|}
\hline \multirow[b]{2}{*}{ Serviços Oferecidos (Pacotes) } & \multicolumn{2}{|c|}{$\mathbf{A}$} & \multicolumn{2}{|r|}{$\mathbf{B}$} & $C=(B \div A)$ \\
\hline & & $\begin{array}{l}\text { ramento } \\
\text { tencial }\end{array}$ & & $\begin{array}{l}\text { Renda } \\
\text { tencial }\end{array}$ & $\begin{array}{l}\text { Margem } \\
\text { Bruta }\end{array}$ \\
\hline Diária com alimentação & $\mathrm{R} \$$ & 686.99 & $\mathrm{R} \$$ & 506.89 & $74 \%$ \\
\hline Diária sem alimentação & $\mathrm{R} \$$ & 221.48 & $\mathrm{R} \$$ & 176.84 & $80 \%$ \\
\hline Alimentação a parte (almoço ou jantar) & $\mathrm{R} \$$ & 574.54 & $\mathrm{R} \$$ & 353.00 & $61 \%$ \\
\hline Trilhas por grupo de até 10 pessoas & $\mathrm{R} \$$ & 148.65 & $\mathrm{R} \$$ & 136.88 & $92 \%$ \\
\hline Farinhada para grupo de até 10 pessoas & $\mathrm{R} \$$ & 222.97 & $\mathrm{R} \$$ & 211.20 & $95 \%$ \\
\hline Canoagem para grupo de 5 , passeio de canoa & $\mathrm{R} \$$ & 148.65 & $\mathrm{R} \$$ & 142.11 & $96 \%$ \\
\hline Monitoria na Oficina de Artesanato , $\mathrm{p} / 5$ pessoas & $\mathrm{R} \$$ & 50.19 & $\mathrm{R} \$$ & 34.85 & $69 \%$ \\
\hline Média Ponderada & $\mathrm{R} \$$ & $2,053.46$ & $\mathrm{R} \$$ & $1,561.76$ & $76 \%$ \\
\hline
\end{tabular}

Fonte: PORTO, N.P. FILHO, L.F,2014

Source: PORTO, N.P. FILHO, L.F,2014.

Para obter a Renda Real proporcionada pelo TBC na comunidade Nova Esperança, multiplicou-se o resultado ponderado da Margem Bruta pelo Faturamento Real de $R \$ 50.00$, Renda Real de $R \$ 266.19$, sendo a Margem Bruta 76\%. As análises deram o resultado ilustrado na Figura 7 comparando a Renda Real do TBC na Comunidade Nova Esperança versus a Renda Potencial. 




Figura 7: Renda Potencial vs Renda Real do TBC

Figura 7: Potential Income vs Real Income

Fonte: PORTO, N.P. FILHO, L.F,2014.

Source: PORTO, N.P. FILHO, L.F,2014.

A análise demonstra que a renda real é ainda muito abaixo da capacidade real de auferir renda com o TBC nesta comunidade. Há uma disparidade de entre o real e o potencial. Portanto, é necessário tomar medidas corretivas para o mínimo de equilíbrio entre as oportunidades de Renda.

No turismo comunitário na comunidade, o custo de oportunidade pode ser observado na escolha entre trabalhar recebendo um grupo de turistas e deixar de ir para roça no mesmo período. A diária para trabalhar na roça é de $\mathrm{R} \$ 30,00$ (Trinta reais), enquanto uma hora de recepção de turistas, canoagem e monitoria de artesanato é em média $R \$ 50,00$ (Tabela 3).

Tabela 3: Receita bruta das atividades comuns na comunidade.

Table 3: Gross Revenue of the ordinaries community's activities.

\begin{tabular}{|c|c|c|}
\hline $\begin{array}{c}\text { Descrição da fonte de } \\
\text { receita }\end{array}$ & Valor da diária $\mathbf{R} \$$ & Valor da hora trabalhada $\mathbf{R} \mathbf{\$}$ \\
\hline Roça & $30,00 / 4 \mathrm{~h}$ & 7,50 \\
\hline Trilha & $50,00 / 1 \mathrm{~h}$ & 50,00 \\
\hline Monitoria do artesanato & $50,00 / 1 \mathrm{~h}$ & 50,00 \\
\hline Canoagem & $50,00 / 1 \mathrm{~h}$ & 50,00 \\
\hline Farinhada & $\begin{array}{c}75,00 / 1 \mathrm{~h} \\
\text { Escolhas levando em } \\
\text { consideração a receita } \\
\text { bruta }\end{array}$ & $\begin{array}{c}\text { Para cada hora trabalhada na roça, se deixa de receber } \mathrm{R} \$ 42,50 \\
\text { com atividade de trilha, na monitoria de artesanato e na canoagem. } \\
\text { E na farinhada } \mathrm{R} \$ 67,50 .\end{array}$ \\
\hline
\end{tabular}

Fonte: PORTO, N.P. 2013. Source: PORTO, N.P. 2013. 
A cada hora trabalhada na roça, está se abrindo mão do custo de oportunidade dependendo da escolha. Se a opção for pelas atividades de trilha, monitoria de artesanato e canoagem, deixa-se de receber $R \$ 42,50$ (Quarenta e dois reais e cinquenta centavos); se for na farinhada, deixa-se de receber $R \$ 67,50$ (Sessenta e sete reais e cinquenta centavos).

Levando em consideração a receita bruta é preciso refletir sobre as vantagens comparativas analisando-se, por exemplo, quanto a roça rende de produtos para cesta mensal de uma família. É importante lembrar que o custo de oportunidade remete a valores implícitos e, portanto, muito subjetivos, que podem ir além de análises de depreciações físicas como por exemplo: o desgaste físico causado pelo sol e tempo de esforço aplicados nas atividades de roça e pesca versus o esforço para desempenhar atividade turística. O turismo comunitário, com seu papel social, cultural e econômico (alternativa complementar de renda), é um importante instrumento para a valorização destas comunidades, podendo evitar a substituição das atividades rurais cotidianas por atividades urbanas.

Portanto, observou-se em campo que atividades complementares como farinhada, canoagem, artesanato e oficina de artesanato são atividades importantes de valorização da vida social ribeirinha. Já os mercadinhos e vendas de camisas com serigrafias, podem ser consideradas atividades que podem substituir as atividades locais, uma vez que, geram lucros muito acima do esperado, podendo influenciar nas escolhas e na substituição natural das atividades tradicionais. Isto pode ser positivo no que concerne à geração de renda, porém perigoso na vida social de uma comunidade tradicional.

Os resultados financeiros desta análise não afirmam ou estimulam que o empreendedor comunitário somente terá que escolher uma das 4 opções de atividades. Considerando-se as dinâmicas ambientais, com diferentes opções de atividade econômica, o comunitário poderá decidir qual atividade lhe proporcionará maior bem-estar social, dependendo das oportunidades para execução da referida atividade. Por exemplo, se o momento não é propício para pesca ou está em baixa estação turística, o comunitário poderá decidir entre produção de artesanato ou roçado e assim por diante. Portanto, a pluralidade do uso dos recursos é necessária para equilibrar a renda mensal das famílias e também maior satisfação das pessoas envolvidas com atividade.

\section{Principais desafios da sazonalidade da atividade turística}

O principal objetivo com a utilização de ferramentas participativas é identificar os problemas no contexto atual do Turismo Comunitário na comunidade objeto de estudo e, a partir de então elaborar um planejamento com a proposição de recomendações estratégicas para amenizar a vulnerabilidade e os impactos das atividades de turismo, otimizando os seus benefícios. 
A utilização da ferramenta "árvore de causa e efeito" trouxe à tona o principal desafio que é a falta de regularidade das visitações na comunidade. Isso é causado pela falta de comunicação entre os comunitários e os donos de barcos e agência de Manaus, gerando uma falta de comprometimento de uma agenda séria e regular entre as partes envolvidas. Mais uma vez, a questão da comunicação está em foco. Muitas vezes, a situação é justificada pela baixa do nível do Rio Cuieiras, que ocasiona a dificuldade de acesso de barcos e lanchas maiores, aumentando a distância até o porto da comunidade. Isso ocasiona a diminuição das vendas de artesanato, baixa na renda familiar mensal, gerando decepção e desmotivação nos comunitários (Tabela 4).

Tabela 4: Calendário Sazonal

Table 4: Seasonal Calendar

\begin{tabular}{|c|c|c|c|c|c|c|c|}
\hline Atividades & Mai-12 & \begin{tabular}{|l|} 
Jun-12 \\
\end{tabular} & \begin{tabular}{l|l} 
Jul-12 & Agos-12 \\
\end{tabular} & \begin{tabular}{|l|l|} 
Set-12 & Out-12 \\
\end{tabular} & \begin{tabular}{|l|l|} 
Nov-12 & Dez-12 \\
\end{tabular} & \begin{tabular}{|l|l|} 
Jan-13 & Fev-13 \\
\end{tabular} & \begin{tabular}{|l|l|l|} 
Mar-13 & Abri-13 & Mai-13 \\
\end{tabular} \\
\hline \multicolumn{8}{|l|}{ Artesanato } \\
\hline \multicolumn{8}{|l|}{ Turismo } \\
\hline \multicolumn{8}{|l|}{ Roça } \\
\hline \multicolumn{8}{|l|}{ Pesca } \\
\hline Caça & & & & & & & \\
\hline
\end{tabular}

As soluções propostas pelo grupo para se vencer tais desafios, foram: melhorar a comunicação entre comunitários e empresários de turismo; diversificar os produtos e serviços turísticos; dialogar periodicamente com as agências sobre a melhoria dos produtos e serviços turísticos potenciais na comunidade; planejar formas de motivar e cativar os visitantes; e buscar outros mercados para o escoamento do artesanato, para que ele não fique atrelado à demanda turística local.

Os resultados de todos os métodos aplicados ajudaram a qualificar a atividade do Turismo Comunitário e elencar vários fatores que ampliam a discussão sobre os aspectos sociais e ambientais na comunidade estudada, conforme se descreverá nos tópicos subsequentes.

\section{As vantagens da adesão ao Turismo Comunitário}

A questão ambiental é importante marco para o desenvolvimento do turismo dentro de RDS. A tendência socioambiental aponta o turismo como uma das principais formas de revalorização da natureza e da cultura local, utilizando estes recursos como ativos econômicos. Portanto, várias iniciativas apoiadas pelo Ministério do Turismo são projetos no interior ou no entorno de áreas protegidas.

Existe uma forte relação entre TC e populações tradicionais e entre TC e Áreas Protegidas. Mesmo com todas as medidas de incentivo ao turismo em AP, elas ainda são insuficientes no que se refere a políticas públicas e legislação, que atendam às singularidades das atividades turísticas de base comunitária em áreas protegidas no Brasil, mais 
especificas ainda ao se tratar de Amazônia. O sistema nacional criado no ano de 2000 definiu regras e normas de uso em unidades de conservação (SNUC), entretanto, persistem focos de tensão sobre as comunidades que habitam áreas transformadas em unidades de conservação para desenvolverem suas atividades tradicionais. Este caso de tensão e instabilidade foi observado na área de estudo desta pesquisa principalmente dúvidas sobre quais áreas poderiam explorar para subsistência e atividades poderiam exercer dentro da UC.

O Turismo Comunitário traz o sentido de valorização do local e das pessoas visto que o que será oferecido para o turista vem do olhar dos comunitários sobre si e não um agenciamento externo ditando o que é deve ser. O intercâmbio e as relações são fundamentais nessa construção, pois relações econômicas são enriquecidas por outras relações que ultrapassam a racionalidade do lucro imediato.

Durante a pesquisa de campo observou-se algumas vantagens de se trabalhar com o turismo numa escala menor. A alimentação pode ser fornecida com ingredientes locais, evitando o transporte de insumos; consome-se verduras e frutas orgânicas; e garante a circulação da moeda internamente.

As caminhadas em trilha e canoagem substituem atividades de turismo convencional como uso de motor fluvial e lancha. Na utilização de canoas a remo, não se queima combustível, evitando assim danos ao meio ambiente.

$\mathrm{Na}$ hospedagem, observou-se uma infraestrutura de menor impacto visual, consumo menor de energia e material de construção civil menos impactante ao meio ambiente. Em relação ao consumo da água, percebeuse que na Comunidade Nova Esperança é garantido de forma abundante pelo fato de haver poço artesiano comunitário que abastece todas as famílias das comunidades.

$\mathrm{Na}$ análise dos custos sociais do TC na comunidade, levou-se em consideração o cálculo do uso da água na preparação dos serviços e da emissão de carbono pela queima de combustível para geração de energia no gerador comunitário. A estratégia metodológica de levantamento de despesas para a sugestão de melhores práticas de organização financeira foi realizada por meio de estudos de custos e benefícios marginais, que variam de acordo com o aumento de uma unidade adicional e que levam em conta a decisão de custos-benefícios por um produto ou serviço. Considerou-se despesas todos os gastos que uma empresa ou negócio precisa para obter uma receita. A análise levou em consideração todos os insumos e horas de trabalho necessário para desenvolver atividade de turismo e produtos associados ao turismo numa perspectiva de diferentes cenários (otimista, pessimista e real).

É importante destacar que, neste trabalho, todas as referências à renda, inclusive no que tange á renda justa da atividade turística de pequena escala, considera-se a hora-trabalhada em $\mathrm{R} \$ 3,85$ (Três reais e oitenta e 
cinco centavos) - equivalente a um salário mínimo do ano de 2013 de $\mathrm{R} \$ 678,00$ (Seiscentos e setenta e oito reais).

Para a análise econômica desta pesquisa adotou-se dois conceitos importantes defendidos por Kahn (2004): que considera os Custos Privados, os quais se referem àqueles custos percebidos pelos prestadores de serviço, como os custos de insumos ou os custos de matéria-prima; como também os chamados Custos Sociais, os quais se referem aos custos das externalidades sociais e ambientais e que são, geralmente, despercebidos pelos prestadores de serviço ou pelos consumidores do serviço.

A desconsideração dos Custos Sociais é uma característica presente em mercados - mesmo naqueles de nações desenvolvidas - e produz falhas de mercado (locais ou globais) ao não contabilizar as externalidades sobre a sociedade e o meio-ambiente. Nesta pesquisa foi necessário buscar o conhecimento e clareza das influências internas e externas sobre esta atividade para uma melhor eficiência operacional e social. Por se tratar de turismo em AP, deu-se a oportunidade de se analisar a qualidade do uso dos recursos ambientais também.

Segundo Kahn (2004), o valor dos serviços ambientais não pode ser medido por uma unidade direta, mas indireta e representativa, ou seja, não é possível se medir a potabilidade da água, ou o valor dos serviços da biodiversidade. Quanto a este dilema, a ciência econômica, voltada para valoração dos serviços ambientais, propõe que a valoração seja realizada através de unidades que representem os referidos serviços e que tenham preço reconhecido no mercado. Assim, na presente investigação, os Custos Privados (CP) e os Custos Sociais (CS) foram mensurados por meio das medidas de carbono e litros de água utilizados no processo (quantitativamente, como unidade de medida representativa). Para a análise dos impactos sobre os serviços ambientais, na mensuração dos "Custos Marginais Sociais" foram utilizadas duas unidades de representação do CS:

1 - Custo da água: medida pelos litros de água utilizados na limpeza e higienização do ambiente para o turista, ou pelo uso do próprio turista, durante sua estadia. Sua valoração é medida pelo preço do metro cubico $(\mathrm{R} \$ 5,16)$, transformado para unidade de litros de água cobrado pela Cia de Águas de Manaus o valor cobrado do litro é $(R \$ 0,0051)$. O cáculo utilizado foi: Cs água = La $\times$ Pa. Sendo o Cs é o custo da água, La Litros de água e $P a$ Preço da água.

2 - Custo das emissões de carbono: A medição é feita pelo uso de cada litro de gasolina/diesel utilizados no transporte até a comunidade e o retorno à sede municipal de Manaus, bem como para uso dos motores locais para geração de energia-elétrica. Segundo Soares et al., (20094) considerase que toda a cadeia de produção, distribuição e utilização de combustíveis fósseis, cada litro de gasolina emite até $3,65 \mathrm{~kg}$ de carbono. Para a valoração do carbono emitido foi considerado, como preço de referência o valor de $\mathrm{R} \$ 8,75$ (Oito reais e setenta e cinco centavos) por tonelada de carbono, 
negociados na BM\&F Bovespa ${ }^{5}$, em junho de 2012 - corrigidos com a inflação acumulada até junho de 2013 .

O cálculo utilizado foi $\mathbf{C S c c}=[(\operatorname{Lg} \times 3,65 \mathrm{Kg}) \div 1000]$ x Pcc. Sendo que CScc custo do serviço do carbono, $\mathbf{L g}$ é o Litro de gasolina, emissão de carbono por litro de gasolina $(\mathbf{3 , 6 5} \mathbf{~ k g})$ e $\boldsymbol{P} \boldsymbol{c c}$ preço de créditos de carbono.

Outro conceito importante utilizado na análise, diz respeito ao custo de oportunidade, que não é propriamente o que se ganha ou o que se perde em uma escolha, mas o que se deixa de ganhar.

Segundo Nascimento (1998), é uma análise de várias alternativas de ação, onde o benefício que obterá em relação ao sacrifício de alternativas de ação correspondentes será o melhor possível nas circunstâncias em que a decisão (escolha) está sendo tomada. Trata-se de custos implícitos que não necessariamente são monetários. Por meio da definição do custo de oportunidade, foi possível comparar os valores de margem de contribuição média potenciais entre as atividades econômicas de cada uma das comunidades, analisando as vantagens comparativas entre elas.

Nesta análise, o conceito utilizado para renda é o rendimento para os gastos da família; enquanto faturamento é o valor bruto arrecadado, também chamado de receita bruta, que é referente ao total arrecadado com a prestação do serviço. Do total arrecadado na Receita Bruta, serão pagas as despesas de insumos. O valor referente à renda diz respeito ao montante arrecadado pela família para cobrir suas despesas pessoais. Ou seja, o valor de renda, já desconsidera as despesas de insumos, usados no empreendimento. Com os dados obtidos por meio dos formulários aplicados em cada família foi possível calcular o Faturamento Médio Real Mensal (FMRM) das duas comunidades. Particularmente neste trabalho, 0 Faturamento também será considerado como a Receita Mensal Familiar (RMF).

A pesquisa se propôs analisar a rentabilidade de cada serviço relacionado à cadeia produtiva do turismo, ou seja, cada serviço deveria ser analisado individualmente. Logo, a análise teria que ser unitária. Nos casos de análises unitárias, o custo fixo unitário varia conforme a variação da quantidade vendida. Já a análise agregada de faturamento varia na análise individual, se a quantidade vendida dobra ou triplica. Assim sendo, optou-se por não se considerar o custo fixo unitário, mas a margem anterior a ele, chamada Margem de Contribuição (MC). Portanto, não foi utilizado o conceito de Margem de Lucro (ML), que é quando se analisa um negócio como um todo, onde os custos fixos não variam, mas sim o de Margem de Contribuição.

Margem de Contribuição é o valor de venda descontado de todos os custos de produção. Após se retirar todos os custos operacionais de produção, o que sobra "contribui" para pagar o custo fixo e pagar o "custo empresarial", este último comumente chamado de "lucro" (MOURÃO, 2009). 
Para determinar a Margem de Contribuição (MC) foi necessário ter informações sobre o Custo da Mão de Obra (CMO), Custo Privado e Social (CPS) e a Capacidade Máxima de Serviço (CMS). Para definir a CMS, foi considerada a carga horária de 44 horas semanais, um total de 176 horas úteis mensais, em obediência ao regime da CLT (Considerações das Leis de Trabalho), permitindo um total de 22 diárias ao mês. Os cálculos financeiros realizados para demonstrar os resultados esperados na análise econômica foram são demonstrados na Tabela 5.

Tabela 5: Cálculos financeiros da análise econômica.

Table 5: Financial calculations of economic analysis.

\begin{tabular}{l} 
Resultado do cálculo \\
\hline Faturamento Médio Real \\
Mensal (FMRM) \\
Receita Média Mensal do \\
Turismo (RMMT)
\end{tabular}

Faturamento Médio Mensal das famílias com atividade turística (FMMT) Incremento de Receita com Turismo (IRT)
Descrição do cálculo É a soma da Receita Média Familiar

(RMF) dividida pelo Número de Famílias $\quad F M R M=\sum R M F \div N F$ (NF).

É a soma de todas as Receitas oriundas do Turismo (RT) divididas por 12 meses do ano.

\section{Fórmula do cálculo}

$R M M T=\sum R T \div 12$

\begin{tabular}{|c|c|}
\hline $\begin{array}{l}\text { É a subtração do Faturamento Médio Real } \\
\text { (FMR) da Receita Média Mensal do } \\
\text { Turismo (RMMT) }\end{array}$ & $F M M T=F M R-R M M T$ \\
\hline É a divisão da Receita Média Mensal do & \\
\hline $\begin{array}{l}\text { Turismo (RMMT) pela subtração do } \\
\text { Faturamento Médio Real Mensal (FMRM) } \\
\text { da Receita Média Mensal do Turismo } \\
\text { (RMMT) e o resultado é multiplicado por } \\
100 .\end{array}$ & $\begin{array}{l}I R T=[R M M T /(F M R M- \\
R M M T) X 100]\end{array}$ \\
\hline $\begin{array}{l}\text { É a subtração da Receita Total }(R T) \text { pelos } \\
\text { Custos dos Serviços Prestados }(C S P) \text {. }\end{array}$ & $M B=R T-C S P$ \\
\hline $\begin{array}{l}\text { É a diferença entre Faturamento pelos } \\
\text { Custos dos Insumos }(\mathrm{Cl})\end{array}$ & $R=F-C l$ \\
\hline
\end{tabular}

\begin{tabular}{|c|c|c|}
\hline Renda Potencial (RP) & $\begin{array}{l}\text { É o resultado da divisão Total de Hora } \\
\text { (TH) pela do Hora Serviço (HS) } \\
\text { multiplicado pelo }(C S P)\end{array}$ & $R P=(T H \div H S) \times C S P$ \\
\hline $\begin{array}{l}\text { Margem de Contribuição } \\
\text { (MC) }\end{array}$ & $\begin{array}{l}\text { É a diferença entre Receita Total }(R T) \text {, } \\
\text { Custo Privado e Social (CPS), Custo da } \\
\text { Mão de Obra (CMO) e a Capacidade } \\
\text { Máxima de Serviço (CMS) }\end{array}$ & $\begin{array}{l}M C=[(R T-C P S-C M O-C M S) \\
\div R T] \times 100\end{array}$ \\
\hline
\end{tabular}

\begin{tabular}{lll}
$\begin{array}{l}\text { Renda Média Potencial } \\
\text { (RMP) }\end{array}$ & $\begin{array}{l}\text { É o resultado da subtração da Receita } \\
\text { Total (RT) do Custo de Serviços } \\
\text { Prestados(CSP) dividido pelo Valor da } \\
\text { Hora }(V H)\end{array}$ & $R M P=(R T-C S P) \div V H$ \\
\hline Renda Média Real (RMR) & $\begin{array}{l}\text { É a multiplicação entre o Faturamento } \\
\text { Médio Real (FMR) e a Margem Bruta }\end{array}$ & $R M R=F M R \times M B$
\end{tabular}
(MB).

\begin{tabular}{ll} 
Margem de Contribuição & É a multiplicação do Faturamento Médio \\
Média Potencial (MCMP) & Potencial (FMP) de cada atividade \\
em $\boldsymbol{R} \$$ & $\begin{array}{l}\text { baseada na hora de trabalho de cada uma } \\
\text { delas pela Margem de Contribuição Média } \\
\text { Potencial }(M C M P) \text {, o resultado é dividido } \\
\text { por } 100 .\end{array}$ \\
\hline
\end{tabular}

Fonte: PORTO, N.P., 2014. Source: PORTO, N.P., 2014. 
Chegou-se a conclusão que as comunidades têm os custos de aproximadamente de $\mathrm{R} \$ 0,01$, sendo portanto um índice insignificante no que se refere aos danos ambientais.

O impacto econômico do turismo ficou bastante evidenciado em Nova Esperança, onde o empreendimento que hospeda visitantes foi transformado sensivelmente nos últimos anos. Isto foi resultado dos reinvestimentos das receitas provenientes da venda de artesanato e hospedagem, o que encorajou os empreendedores a investirem no negócio. A figura 6 ilustra a evolução das benfeitorias realizadas para receber visitantes.

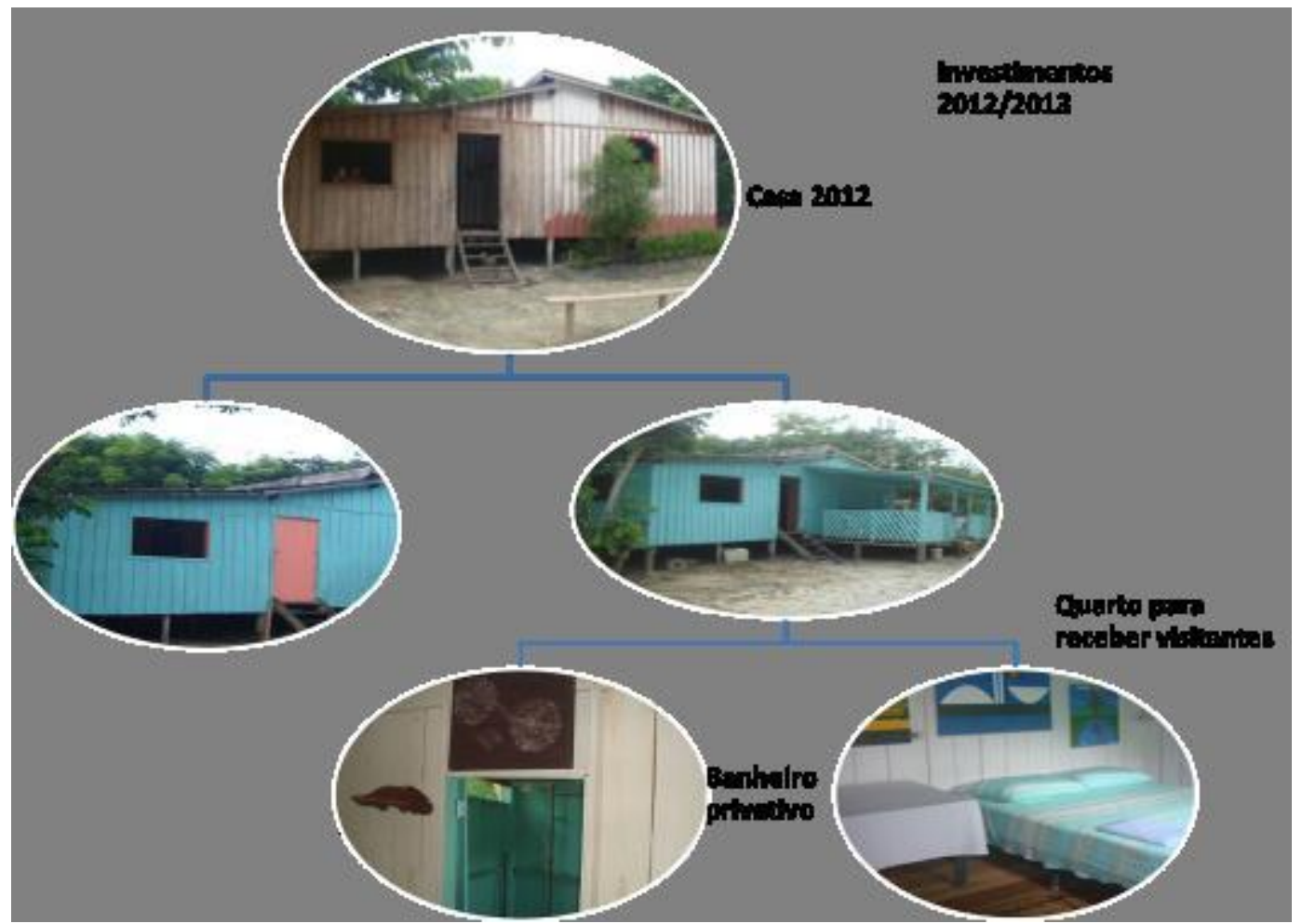

Figura 8: Benfeitorias na casa para hospedar turistas.

Figure 8: Improvement made it in a communitarian house to receiving tourists Fonte: PORTO, N.P., 2014. Source: PORTO, N.P., 2014.

De acordo com o que mostra a figura 6, o início da recepção de visitantes de Turismo Comunitário em Nova Esperança fez com que alguns empreendedores comunitários começassem a investir em acomodações em suas residências. Como por exemplo a construção de um quarto, com banheiro, cama de casal e lugar para uma rede. A hospedagem é um serviço iniciado no Roteiro Tucorin. 


\section{Considerações Finais}

A Comunidade Indígena Nova Esperança iniciou seus trabalhos com Turismo Comunitário com a perspectiva de ter mais uma alternativa de renda. Porém, não se deve esquecer das bases conceituais que inspiram esta modalidade de turismo, que é a sustentabilidade ambiental e a valorização cultural.

O Turismo Comunitário atualmente nesta comunidade é encarado como uma oportunidade de reconhecimento de um grupo de pessoas empreendedoras que buscam trabalhar em uma atividade legal dentro de Áreas Protegidas. No entanto, percebeu-se que o acesso a este mercado de turismo ainda é desafiador para esta comunidade.

Este pode ser também um caminho para a valorização de práticas sociais na comunidade e para 0 cuidado de sentimento ao empreendedorismo social, que poderá ser estimulado por meio de atividades e serviços para o bem da coletividade. Em campo observou-se que na comunidade os serviços e produtos turísticos são empreendimentos familiares, o que agrega valor à atividade no baixo Rio Negro. Embora os empreendimentos sejam familiares, as pessoas envolvidas se reconhecem como um grupo de turismo, e portanto, levam muito a sério as funções das quais são incumbidos.

Muitas atividades turísticas estão diretamente ligadas às suas atividades rotineiras. A farinhada e 0 artesanato não tiram os indígenas de suas práticas cotidianas, gerando ainda produção para o consumo. Isso contribui para a revitalização cultural das comunidades, que por meio dos produtos associados à atividade turística, como é o exemplo do artesanato: gera renda e favorecem o aprendizado e a valorização cultural.

Atenta-se que com o aumento do poder aquisitivo das famílias que trabalham com o turismo, cresceu a demanda por produtos "da capital", sendo este um marcador de diferença social dentro da própria comunidade, de quem tem tais "bens" ou produtos tecnológicos. E isso vai refletir também em quem tem "mercadinho" na comunidade ou quem vai e fica com mais frequência em Manaus. Essa diferenciação, entretanto, vai além do turismo, pois o turismo traz a renda, mas ele não traz "a mudança" ou o "desejo" pelo consumo. No contexto local, a comunidade possui uma frequente relação com outras comunidades indígenas e ribeirinhas, além do contato usual com a capital.

É importante ressaltar isso, pois os comunitários não são sujeitos passivos no processo de apropriação e dialética entre comunidade e cultura \& modernidade e consumo, ao contrário, eles se relacionam diretamente com vários aspectos que moldam e adaptam seus modos de vida indígena, que facilitam a vida de que mora em área rural. Percebeu-se que o modo de vida indígena na comunidade está presente: na união familiar, nas atividades em conjunto, no respeito aos mais velhos, em tentar manter o nheengatu vivo por meio da escola, pelo ensinamento e sabedoria dos mais velhos, pelo cuidado com o seu território, pela valorização de sua cultura, pela 
realização anual de suas festividades, pela própria identificação como indígena Baré.

Devemos entender que em um mundo (e em um país e continente tão desigual como o Brasil e a América Latina), onde se tem como ordem para viver e sobreviver "o capital", independente de qual seja a atividade econômica, a comunidade indígena precisa de recursos financeiros para ter o mínimo de conforto para comer, vestir, estudar, ter lazer, ter seus empreendimentos. E essa é uma necessidade ainda mais acentuada quando as comunidades tem proximidade com a realidade da capital, que é o caso da comunidade em pesquisa.

A apropriação de aspectos da vida que estão presentes na vida na capital tem muito a beneficiar essas comunidades, a exemplo, de indígena se formando em Universidade Estadual; de indígena sendo diretor(a) e professor(a) da escola da comunidade; de indígena tem seu próprio negócio de acordo com a realidade e local; de indígena que está na capital estudando e trabalhando em um negócio de artesanato que revende produtos da comunidade; entre outros exemplos de Nova Esperança.

Com relação à autoestima, percebeu-se que os comunitários estão estimulados a melhorar cada vez mais seus empreendimentos para receber visitantes. Os empreendedores se engajam em participar ativamente de oficinas e reuniões para a melhoria da organização local. Essa característica é reforçada por meio dos depoimentos a seguir, colhidos das entrevistas informais, que registram a satisfação em estar desempenhando as atividades e que também reforçam o princípio do TC, que é a troca de experiência e a satisfação de receber bem:

\begin{abstract}
"Antes, os turistas só paravam pra comprar o artesanato e iam embora. Agora eles sentam pra conversar, perguntam o que a gente faz, como é a nossa vida e também contam um pouco sobre eles, criando um vínculo de amizade". (Juliana, da Comunidade Nova Esperança, sobre a mudança de comportamento dos novos visitantes trazidos pelo TC).
\end{abstract}

As parcerias e relações sociais com instituições não governamentais foram pontos importantes para o desenvolvimento de capacidade e planejamento do TBC na comunidade. As instituições investiram em capacitação e acompanharam o desenvolvimento das atividades.

Assim, as parcerias se tornam uma importante base de apoio para o desenvolvimento desta atividade. É imprescindível que estes empreendedores tenham uma visão clara de que esta atividade também é um negócio, e como tal, deve buscar o aprimoramento constante a fim de garantir sua sustentabilidade enquanto atividade socioeconômica.

Com isso, acredita-se, que será possível chegar ao mercado de forma mais competitiva, garantindo a sustentabilidade tanto dos custos privados 
quanto sociais. A sua consolidação enquanto atividade, garantirá o sucesso dos empreendimentos locais e a manutenção da autoestima dos protagonistas envolvidos no processo. Como consequência, o aumento das boas experiências de TC em áreas protegidas atrairá novos adeptos para esta nova interface da economia socioambiental.

\section{Referências}

AMAZONAS, Secretaria da Região Metropolitana de Manaus - SRMM. Plano de Desenvolvimento Sustentável e Integrado da Região Metropolitana de Manaus 2010-2020. Manaus, 2010.

BRANDÃO, C. R.; STRECK, D. R. (org.). Pesquisa participante: o saber da partilha. Aparecida, 2006.

BRASIL, Decreto $n^{\circ} 5.758$, de 13 de abril de 2006. Plano Estratégico Nacional de Áreas Protegidas. 2006. Disponível em: http://www.mma.gov.br/estruturas/205/_arquivos/planonacionaareasprotegidas_20 5.pdf

BRASIL. Manual de Diretrizes para Visitação em Unidades de Conservação Brasileiras. Brasília: Ministério do Meio Ambiente, 2006. Disponível em: http://www.mma.gov.br/estruturas/ascom_boletins/_arquivos/livro.pdf

BURSZTYN, I. Desatando um nó na rede: sobre um projeto de facilitação do comércio direto do turismo de base comunitária na Amazônia. Rio de Janeiro: UFRJ/COPPE, 2012.

CORIOLANO, L. N. M. T. O turismo comunitário no nordeste brasileiro. In: BARTHOLO, R.; SANSOLO, D. G.; BURSZTYN, I.(orgs.). Turismo de base comunitária: diversidade de olhares e experiências brasileiras. Rio de Janeiro: Letra e Imagem, pp. 277-288, 2009.

DIEGUES, A. C.(org.) Etnoconservação: novos rumos para a proteção da natureza nos trópicos. São Paulo: Hucitec; NUPAU/USP, 2000.

IRVING, M. de A. Reinventando a reflexão sobre turismo de base comunitári: inovar é possível?. In: BARTHOLO, R.; SANSOLO, D. G.; BURSZTYN, I.(orgs.). Turismo de base comunitária: diversidade de olhares e experiências brasileiras. Rio de Janeiro: Letra e Imagem, pp. 108-121, 2009.

KAHN, J. R. The Economic Approach to Environmental and Natural Resources. 3. ed. Lexington: Thompson South Western, 2004.

MALDONADO, C. O turismo rural comunitário na América Latina: gênesis, características e políticas. In: BARTHOLO, R.; SANSOLO, D. G.; BURSZTYN, I.(orgs.). Turismo de base comunitária: diversidade de olhares e experiências brasileiras. Rio de Janeiro: Letra e Imagem, pp. 25-44, 2009.

SEVERINO, A.J. Metodologia do trabalho científico. 23 ed. e atual. SP:Cortez, 2007. 


\section{Agradecimentos}

Agradecemos ao Instituto de Pesquisa Ecológicas pelo apoio logístico a todas as etapas de visita de campo.

Agradecemos à CAPES, pois parte do presente trabalho foi realizado com apoio da Coordenação de Aperfeiçoamento de Pessoal de Nível Superior - Brasil (CAPES) - Código de Financiamento 001.

\section{Notas}

${ }^{1}$ Levantamento feito no Catálogo de Teses e Dissertações da Coordenação de Aperfeiçoamento de Pessoal de Nível Superior - CAPES no Brasil, entre 1998 a 2017, nos quais: a) turismo de base comunitária (51 mestrados, 19 doutorados, 1 edital do órgão oficial de turismo do Brasil); b) turismo comunitário (41 mestrados, 10 doutorados); c) ecoturismo de base comunitária ( 5 mestrados); d) turismo de base local (14 mestrados, 1 doutorado); e) turismo solidário (4 mestrados, 2 doutorados); f) turismo rural comunitário (5 mestrados); e g) turismo rural sustentável (3 mestrados).

${ }^{2}$ A Nymuendajú é uma Organização Não-Governamental que atua na Amazônia.

${ }^{3} \mathrm{O}$ IPÊ se caracteriza como uma OSCIP (Organização da Sociedade Civil de Interesse Público) atuante nas cinco regiões brasileiras.

${ }^{4}$ Disponível em: http://www.infoteca.cnptia.embrapa.br/bitstream/doc/630482/1/cit027.pdf. Acesso em: 10/11/2013.

${ }^{5}$ BM\&F Bovespa S.A - Bolsa de Valores, Mercadorias e Futuros (antiga Bolsa de Valores de São Paulo). Mede o comportamento das ações mais negociadas e indica o desempenho médio das cotações de uma carteira teórica de ações negociadas no pregão. Disponível em: www.bmfbovespa.com.br/pt-br/download/Ata-do-Leilao.pdf. Acesso em: 17/12/2013.

Nailza Pereira Porto: Instituto de Pesquisas Ecológicas, Nazareth Paulista, SP, Brasil

E-mail: nailzatur@hotmail.com

Link para o currículo Lattes: http://lattes.cnpq.br/9609741765510707

Ana Rosa Guimarães Bastos Proença: Universidade de São Paulo, São Paulo, SP, Brasil

E-mail: anarosaproenca@usp.br

Link para o currículo Lattes: http://lattes.cnpq.br/7961591481023349

Data de submissão: 28 de fevereiro de 2019

Data de recebimento de correções: 21 de junho de 2019

Data do aceite: 21 de junho de 2019

Avaliado anonimamente 